\title{
Teologies-etiese perspektiewe op die 1996- grondwet van die Republiek van Suid-Afrika
}

\author{
J.M. Vorster \\ Dept. Dogmatologie en Ekklesiologie \\ Potchefstroomse Universiteit vir $\mathrm{CHO}$ \\ POTCHEFSTROOM
}

\begin{abstract}
Theological-ethical perspectives on the 1996 Constitution of the Republic of South Africa

The acceptance of the 1996 Constitution of the Republic of South Africa must be seen as a historical event. For the first time in its history this country is governed by $a$ widely accepted democratic Constitution. The chapter on fundamental rights is also a new contribution to government in South-Africa. Although the final draft of the Constitution was endorsed by the vast majority of political parties and communities, criticism from various groups was also heard. This article is an attempt to evaluate the Constitution from a Reformed theological-ethical point of view. Attention is paid to the principles of justice, order and religious freedom. and the way in which these principles manifest in the Constitution. The task of the Church in the promotion of a culture of democracy and humain rights is also emphasised.
\end{abstract}

\section{Inleiding}

Die grondwet van 1996 is 'n besondere mylpaal in die Suid-Afrikaanse geskiedenis. Vir die eerste keer in die bestaan van die land is daar 'n grondwet waaraan alle sektore van die bevolking meegewerk het. Die proses het bykans twee jaar geduur en voorleggings vanuit die wye spektrum van die SuidAfrikaanse samelewing is in dié tyd deur die grondwetskrywende vergadering oorweeg (CARSA, 1996:33). Dit op sigself is 'n opvallende positiewe aspek van die nuwe grondwet. Aan die ander kant het dit duidelik geword dat nie alle politieke partye die grondwet in sy geheel onderskryf nie, hoewel die meerderheid dit as grondwet aanvaar. Hiervoor is verskeie redes vanuit partypolitieke, ideologiese en ekonomiese hoek aangevoer. Uit sommige Christelike kringe is ernstige kritiek teen aspekte van die grondwet uitgespreek soos wat dit algaande in die onderhandelingsproses uitgekristalliseer het (UCA, 1995:1). Voorts moet ook gemeld word dat die proses van konkretisering en die juridiese vormgewing van die Grondwet nou pas begin het en dat baie afhang van interpretasies wat die hof aan die formuleringe gaan gee indien dit getoets word. Sulke interpretasies kan vir Christene in die toekoms bepaalde probleme oplewer. In die debat rondom die grondwet is dit egter nou moontlik om ook vanuit 'n 
gereformeerde oogpunt teologies-eties daaroor te besin juis omdat die koninkryk van God diepgaande implikasies het vir die politiek en die ordening van die samelewing.

Die kernvraag wat in so ' $n$ besinning aan die orde moet kom, is die vraag van verantwoordelikheid aan God. God gee gesag en die owerhede van die wêreld moet aan God rekenskap gee vir die uitvoering van daardie gesag (Rom. 13:1). Hierdie verantwoordelikheid behoort te spreek uit die belydenis wat uitgaan van die grondwet sowel as die aanvaarbaarheid van sy inhoud in die lig van die etiese beginsels van die Bybel. In die lig van hierdie grondliggende beginsel moet dan drie vrae aan so 'n grondwet gestel word. Eerstens moet gevra word of die grondwet reg laat geskied aan die Bybelse beginsel van geregtigheid. Tweedens moet gevra word of die grondwet 'n effektiewe basis sal wees waarop orde in die samelewing gebou kan word, en derdens moet die vraag gevra word of die grondwet ruimte laat vir die kerk van Christus om die evangelie te versprei (Nederlandse Geloofsbelydenis art. 36). Laasgenoemde opset raak dus die beginsel van godsdiensvryheid. In die volgende uiteensetting word op dié vrae ingegaan.

\section{Die teologies-etiese toets van 'n grondwet}

\subsection{Geregtigheid}

Geregtigheid is in die Bybel primêr 'n aanduiding van die herstelde verhouding tussen God en die mens deur die soenbloed van Christus. Hierdie herstelde verhouding het egter ook duidelike implikasies vir sosiale verhoudinge. Geregtigheid vereis ook dat mense mekaar regverdig en billik moet behandel (Kik, 1982:65). Onderdrukking, uitbuiting en verontregting tas die Bybelse beginsel van geregtigheid aan (2 Sam. 12:1-25; Jer. 22:17; Amos 4 en 5:7-13; Miga 6:12). Niemand kan sê dat hy God liefhet terwyl hy sy naaste verontreg nie (1 Joh. 4:20). Hierdie geregtigheid moet nie net gerealiseer word in interpersoonlike verhoudinge nie, maar ook in die vestiging van sosio-politieke en ekonomiese strukture (Saladin, 1982:216). Eloff (1988:341) bevind na deeglike historiese en eksegetiese ondersoek dat die Skrif die vestiging van institusionele geregtigheid vereis. Die daarstel van 'n politieke stelsel wat geregtigheid waarborg, is ' $n$ wesentlike deel van die taak van die owerheid.

'n Gelowige mag dus nie 'n politieke stelsel ondersteun wat lei tot 'n praktyk van onderdrukking en uitbuiting nie. Daarom moet vasgestel word of die grondwet van 'n land uitvoering gee aan die geregtigheidstaak van die owerheid en of dié grondwet die basis is waarop geregtigheid in sosio-politieke sin gebou kan word.

In die moderne staatkunde word die taak van die owerheid verwerklik in die konsep van 'n regstaat. Hierdie begrip beteken dat die Parlement nie op 
pragmatiese wyse wette maak op die basis van die eise van die praktyk volgens norme wat vir daardie situasie alleen bestaan nie, maar volgens 'n voorafvasgestelde beginselbasis. Hierdie beginselbasis word dan vervat in ' $n$ handves van menseregte waaraan wetgewing moet voldoen. Die konsep van menseregte in hierdie sin het oor die afgelope twee eeue in die Westerse wêreld ontwikkel (Lochman, 1976:8). Op verskeie maniere is menseregte gegiet in 'n juridies bruikbare vorm en as basiese regte beskerm (Van der Vyver, 1974:30). Die moderne metode van beskerming is deur middel van 'n konstitusionele hof. 'n Onafhanklike konstitusionele hof word bemagtig om wetgewing aan die hand van die beginsels van die handves te toets.

Menseregte as sodanig is egter ook 'n Bybelse konsep wat sedert die sestiende eeu deur die Protestantse tradisies erken is (Villa-Vicencio, 1992:137; Wingren, 1978:16). Die saak van menseregte kan vanuit verskillende Bybelse perspektiewe belig word (Du Toit, 1988:48). Die beginsel van menseregte in hierdie verband berus op die feit dat die mens beelddraer van God is. Moltmann (1977:132) sê tereg dat die mens as beelddraer van God, in al sy verhoudinge, soos onder andere die ekonomiese, sosiale, politieke en persoonlike verhoudinge, leef voor die aangesig van God. Na 'n deeglike eksegetiese en gereformeerd-konfessionele studie hieroor het die Gereformeerde Ekumeniese Sinode (GES, 1983:97) ook tot die volgende insiggewende konklusie gekom:

Being a creature means being a servant of God (Psalm 119:91). We are under obligation to God for our fellowmen. This is a responsibility no man can escape - even though, due to sin, we can no longer discharge it perfectly. Walking by the light of the Scripture therefore means deepening, broadening, and enriching our sensitivity to the three-dimensional perspective which orders every rights relationship in life - namely 1) our responsibility towards others, and 2) their responsibility towards us, 3 ) all this subsumed under our joint responsibility to God. Or, stated differently: 1) the rightful claims of others upon us, and 2) our rightful claims upon them, 3) all this subsevient to God's comprehensive claim upon us all.

'n Ander denkskool grond menseregte in die aanname dat alle mense kinders van God is (Koshy, 1996:141). Hierdie standpunt is problematies omdat die Bybel duidelik stel dat sondaars kinders van God word alleen deur die geloof in Christus (1 Joh. 3:10). Nie almal is dus kinders van God nie. Om menseregte op hierdie aanname te vestig, is prinsipieel onaanvaarbaar. Die uitgangspunt van die mens as beelddraer van God het veel meer meriete omdat alle mense na die beeld van God geskape is, hoewel die beeldskap deur die sonde erg geskend is.

Hoewel die mens vanweë sy totale verdorwenheid op geen regte teenoor God kan aanspraak maak nie, ken God aan die mens regte teenoor mekaar toe. Hy beskerm die regte van die arme en die vreemdeling en verwag van gelowiges om 
dieselfde te doen (Deut. 10:18-19). Hierdie regte moet teenoor die owerhede (vertikaal) en teenoor mekaar (horisontaal) beskerm word. Die regte konstitueer egter ook veantwoordelikhede. 'n Mens se reg om beskerming van sy lewe stel daarmee saam sy verantwoordelikheid om die lewe van ander te respekteer en andersom.

\subsection{Ordelikheid}

God verwag orde in die samelewing; daarom het hy die owerheid ingestel en aan hom die swaardmag gegee om oortreders te straf. Hy vereis ook van onderdane verantwoordelikheid en gehoorsaamheid aan die owerheid in alle sake wat reg en billik is (Matt. 22:15-22). Onder die beginsel van ordelikheid kom die volgende sake aan die orde: bekamping van misdaad en die middele om dit uit te voer, die handhawing van hoe morele beginsels, die beskerming van die waarheid, die waarborg vir deursigtigheid en die daarstelling van 'n sisteem wat in sigself die moontlikheid van vreedsame protes, opposisie en die verwisseling van regering bevat. Die vraag moet dus gevra word of die grondwet van 'n land ook die basis is waarop 'n ordelike samelewing in bogenoemde terme gebou kan word en waarop deurlopende vreedsame verandering ten goede kan plaasvind.

Van die kant van die onderdaan word gehoorsaamheid aan die owerheid verwag solank die optrede van die owerheid nie die koninkryk van God doelbewus ondermyn nie. In geval van doelbewuste ondermyning van die koninkryk van God moet God, en nie die owerheid nie, gehoorsaam word (Van der Walt, 1983:18). Die Protestantse tradisie het tot dusver deurgaans die reg tot verset in so 'n geval erken (De Gruchy, 1984:98), met ander woorde, die owerheid, selfs die ongelowige owerheid, moet gehoorsaam word totdat bewys kan word dat die owerheid hom direk en aktief teen die koninkryk van God rig (Eloff, 1982:100). Hierdie verantwoordelikheid van die onderdaan moet deur 'n ordelike grondwet moontlik gemaak word. Die vraag moet dus gevra word of die nuwe grondwet van die Republiek van Suid-Afrika dit vir gelowiges moontlik maak om aan die owerheid gehoorsaam te wees met 'n goeie gewete.

\subsection{Godsdiensvryheid}

Die gewysigde teks van die Nederlandse Geloofsbelydenis artikel 36 sê oor die taak van die owerheid die volgende:

... dit is nie alleen hulle taak om aan die staatsbestuur aandag te gee en daaroor te waak nie, maar ook om die heilige Woordbediening te beskerm, om sodoende alle afgodery en valse godsdiens teen te gaan en uit te roei, die ryk van die antichris te vernietig en die koninkryk van Jesus Christus te bevorder, die Woord van die evangelie orals te verkondig, sodat God deur elkeen geëer en gedien word soos Hy in sy Woord beveel. 
Hierdie uitspraak beteken nie dat die owerheid self die Woord moet verkondig en ander godsdienste en ongeloof moet verbied nie, maar dat die owerheid so moet regeer dat die kerk in staat is om sy roeping te vervul. Die kerk moet vry wees om die Woord te verkondig en om deur die verkondiging van die Woord die koninkryk van God te bevorder. 'n Grondwet moet dus ruimte gee aan die kerk om hierdie primêre funksie te vervul deur die erkenning van die reg van godsdiensvryheid (Vorster, 1993:314).

Met die uitdrukking "godsdiensvryheid" word in teologies-etiese sin bedoel: die reg en moontlikheid van godsdienste om vryelik in 'n samelewing te funksioneer volgens die eie beginsels van die betrokke godsdiens. Hierdie reg word tans wêreldwyd as 'n basiese mensereg beskou (Lendvai, 1983:7) Vanweě die Verenigde Volke Organisasie (VVO) se formulering hiervan in artikel 18 van sy Internasionale Deklarasie van Menseregte is die reg van godsdiensvryheid tans wyd gevestig. Dié formulering lui:

Everyone has the right to freedom of thought, conscience and religion, this right includes freedom to change his religion or belief, and freedom either alone or in community with others, in public or private to manifest his religion or belief in teaching, practice worship and observance (GES, 1983:87).

In die gereformeerde etiek word godsdiensvryheid ook as basiese reg beklemtoon (GES, 1983:151; GKSA, 1985:651 en NGK, 1986:31). Godsdienste moet ook gelykheid voor die reg geniet.

\section{Die grondwet teologies-eties getoets}

\subsection{Die aanhef}

In die aanhef van die 1996-grondwet van die Republiek van Suid-Afrika is twee sake opvallend. Eerstens is daar 'n gebrek aan 'n duidelike belydenis van die Drie-enige God as die gewer van gesag en die feit dat die owerheid as gesagsdraer ten diepste aan God verantwoording verskuldig is. Met hierdie weglating is doelbewus gekies vir die konsep van 'n sekulêre staat. Daarmee word bedoel dat die staat lewensbeskoulik neutraal is en nie ' $n$ bepaalde ideologie of godsdiens as basis het nie. Die vraag is egter of so ' $n$ grondwet neutraal kan wees. Alhoewel daar nie 'n duidelike keuse gemaak word nie, moet een of ander lewensbeskouing as voorveronderstelling latent teenwoordig wees. Sekularisme is ' $n$ lewensbeskouing op sigself en met die weglating van die belydenis van God Drie-enig is by implikasie gekies vir sekularisme. Met hierdie leemte word verder die indruk gewek dat die owerheid primêr aan die meerderheid van die bevolking verantwoordelik is en nie aan God nie. So 'n beskouing lei in die praktyk tot pragmatistiese bestuur omdat nie gevra word na die beginsel van 'n 
saak nie, maar na die wil van die meerderheid. Die bede aan die einde van die aanhef om die seën van God sê nie veel nie en is kosmeties van aard. Hierdie seënbede gee nie beslag aan die belangrike saak van verantwoordelikheid aan God nie.

Die vraag is egter of 'n Christelike belydenis aan die begin van 'n grondwet die Christelike karakter van die grondwet noodwendig waarborg. 'n Christelike aanhef kan nog 'n nie-Christelike inhoud tot gevolg hê, soos wat dit inderdaad die geval was met die vorige grondwette van die Republiek van Suid-Afrika waar wetlike diskriminasie toegepas is ten spyte van die Christelike belydenis in die aanhef (Vorster, 1993:314). Aan die ander kant kan ook nie gesê word dat die grondwet inherent sekulêr is omdat 'n positiewe belydenis van die Drie-enige God in die aanhef ontbreek nie. Die grondwet moet uiteindelik aan sy inhoud getoets word. Die vraag moet gevra word of Bybels-etiese beginsels in die inhoud van die grondwet aanwesig is. Dit is die belangrikste toets.

In die tweede plek kan wel gesê word dat die aanhef 'n duidelike verklaring van voorneme bevat waarin die beginsel van demokrasie, die handhawing van maatskaplike geregtigheid en fundamentele menseregte aanvaar word. Daarmee saam word die gelykheid van mense en die verbetering van die lewensgehalte van burgers, onder andere, beklemtoon. Hierdie verklaring is 'n baie positiewe inset omdat die gedagte van 'n regstaat waarin menseregte die norm van wetgewing is, deur die gereformeerde etiek prinsipieel aanvaarbaar is en in moderne demokrasiee met sukses toegepas word. Die verklaring van voorneme in die aanhef gee dus ruimte vir die inskryf van teologies-etiese beginsels in die grondwet wat net so belangrik is as ' $n$ direkte belydenis van die afhanklikheid van God. Die aanhef open dus in hierdie verband die weg vir die daarstelling van egte demokrasie met die handhawing van die beginsels van geregtigheid, ordelikheid en godsdiensvryheid.

\subsection{Geregtigheid}

Die belangrikste prinsipiële sake oor geregtigheid in die nuwe grondwet wat teologies-eties beoordeel kan word, word aangeraak in die hoofstuk wat handel oor die beskerming van menseregte (GVRSA, 1996:7). Ander sake is sake van prakties-politieke aard en kan na gelang van tyd en omstandighede verskil. Die Bybel skryf immers nie politieke en ekonomiese stelsels voor nie. Belangrike regte wat uitdrukking gee aan die Bybelse beginsels word in dié hoofstuk uitgespel. Op die volgende kan gewys word:

\subsubsection{Gelykheid voor die reg}

Gelykheid voor die reg is ' $n$ baie belangrike beginsel om diskriminasie teen individue deur die staat uit te skakel en die vryheid van die individu binne die 
raamwerk van die wet te waarborg. Almal moet regverdig en billik behandel word en moet gelyke toegang hê tot regspraak. 'n Volk is verdorwe wanneer sy regspraak korrup is (Amos 2). Diskriminasie teen mense of groepe deur die owerheid op grond van sosiale, etniese, godsdienstige en kulturele gronde word met die beskerming van hierdie beginsel vermy. Die erkenning van hierdie reg is 'n groot teologies-etiese verbetering op die vorige konstitusies waarin op die basis van die bevolkingsregistrasiewet teen mense gediskrimineer is.

\subsubsection{Beskerming van regte}

Regte moet nie slegs erken word nie, maar moet ook effektief beskerm word. Die grondwet stel dat dit die taak van die staat is om dié regte te beskerm (art. 7:2). Dié beskerming vind plaas deur die Konstitusionele Hof wat vir almal toeganklik is (art. 167:3). Daarbenewens is daar ook 'n menseregtekommissie ingestel wat toesig moet hou oor die proses van beskerming. Hierdie kommissie moet "agting vir menseregte en 'n kultuur van menseregte bevorder; die ontwikkeling, beskerming en verwesentliking van menseregte bevorder en die handhawing van menseregte in die Republiek monitor en die stand daarvan bepaal" (art. 184:1). Dit is duidelik dat die nuwe grondwet erns wil maak met die konsep van 'n regstaat en menseregte wil beskerm. Op hierdie wyse word uitvoering gegee aan die belangrike beginsel van politieke vryheid. Vanuit teologies-etiese hoek moet die ontwikkeling verwelkom word en behoort Christene hulle volle samewerking in hierdie verband te gee.

\subsubsection{Menswaardigheid}

Artikel 10 bepaal: "Elkeen het ingebore waardigheid en is daarop geregtig dat daardie waardigheid gerespekteer en beskerm word." Het mense inherente waardigheid? Benewens dit wat reeds gesê is oor die mens as beelddraer van God, meld Psalm 8:5 dat die mens 'n besondere plek beklee in die skepping van God. König (1994:7) dui met goeie redes aan dat hierdie Psalm 'n merkwaardige lied is oor die grootheid, hoogheid en belangrikheid van die mens. Hierdie belangrikheid het hy egter nie self verwerf nie, maar is deur God aan hom gegee (Du Toit, 1988:62). Daarby moet Jesus se bekommernis oor die nood van mense gelees word (Matt. 25:31-46). Vir God het die mens waarde en daarom moet mense mekaar se waardigheid ook erken en beskerm. Horner (1982:224) sê dat alle menseregte ten diepste in die erkenning van die waardigheid van die mens gefundeer moet word. Hieruit vloei voort, onder andere, die regte wat mense teenoor mekaar het (vgl. ook Kleyn \& Heyns, 1994:26; Visagie, 1994:21). In hierdie opsig voldoen die grondwet aan 'n belangrike Christelike etiese beginsel. 


\subsubsection{Die reg op lewe}

Lewe kom van God af. Hy het lewe geskep; Hy gee die nuwe lewe in Christus en Hy gee ook die ewige lewe aan hulle wat glo. Daarom word lewe in die sesde gebod ook beskerm. Die Christelike etiek kan met reg 'n etiek van lewe genoem word. 'n Hoofstuk oor fundamentele menseregte moet dus die reg op lewe erken en vir die beskerming daarvoor voorsiening maak. Dit word inderdaad in die grondwet gedoen, maar twee probleemgebiede is onaangeraak, naamlik dié van aborsie en doodstraf. Uit teologies-etiese hoek moet aborsie afgewys word omdat dit gaan om die lewe van 'n kind (De Bruyn, 1993:137) Voorsiening moet egter gemaak word vir ' $n$ botsing van regte, soos in vorige wetgewing gedoen is. Die reèling van hierdie sake is wel nog moontlik by wyse van wetgewing wat aan die fundamentele beginsel getoets moet word. Die huidige owerheid het egter gekies vir die wettiging van aborsie op aanvraag. Hoe rym hierdie wetgewing met die reg op lewe? Hierdie saak behoort in die Konstitusionele hof getoets te word en in hierdie opsig sal die interpretasie van die wet in die lig van die beginsel van die reg op lewe interessant wees. Christene behoort hulle egter te beywer om hierdie wet herroep te kry. Doodstraf is enigsins moeiliker omdat etici verskil oor die sake wat doodstraf regverdig. In hierdie verband kon die grondwet, met 'n uitsluitingsklousule by die reg op lewe, voorsiening maak vir die toepassing van die doodstraf in gevalle van moord met verswarende omstandighede (GKSA, 1994:617). Doodstraf moet egter met groot omsigtigheid toegepas word en relevante argumente uit regsoogpunt moet deeglik oorweeg word. In hierdie opsig skiet die hoofstuk oor menseregte tekort en behoort in die toekoms verder oor die gebreke gedebatteer te word.

\subsubsection{Die reg op uitdrukking}

Die reg op uitdrukking word effektief beskerm met bepaalde voorbehoude waar die veiligheid van die staat en van individue op die spel is. 'n Klein byvoeging hierby kon reg laat geskied aan die taak van die owerheid om ook 'n hoogstaande morele orde daar te stel. By artikel 16:2 kon ook verwys word na inligting wat kan lei tot die misbruik van mense - soos veral vroue en kinders in pornografiese materiaal. Die byvoeging sou die verspreiding van pornografie, wat nou toelaatbaar is, aan bande gelê het.

\subsubsection{Die beskerming van die omgewing}

'n Besondere winspunt in die hoofstuk oor menseregte is die bepaling in artikel 24 dat die omgewing ook beskerm moet word. Die mens se roeping tot rentmeesterskap is ' $n$ belangrike teologies-etiese beginsel (Gen. 1:28). Die ekologie word ook al hoe meer belangrik soos wat besoedeling in die moderne wêreld toeneem. Met dié bepaling kan Suid-Afrika vroegtydig aandag gee aan 
die vraagstuk van besoedeling wat in die ontwikkelde wêreld prominent geword het.

\subsubsection{Onderwysregte}

Die vraag moet gevra word of die hoofstuk oor menseregte ruimte bied vir die gelowige ouer om sy doopsbelofte ten opsigte van die onderwys na te kom. Artikel 29:3 bepaal dat ouers op grond van godsdienstige oortuigings privaatonderwysinrigtings kan oprig en dit is in ooreenstemming met die standpunt van die gereformeerde etiek. Die bepaling moet verwelkom word. Artikel 29:2 wat handel oor elkeen se reg om in sy eie taal onderrig te ontvang, is egter vaag en sal nie onregmatige owerheidsinmenging uitskakel nie. Hierdie formulering behoort hersien te word.

\subsubsection{Geslagsgelykheid}

Die Bybel stel onomwonde die gelykheid van die geslagte. Man en vrou is elkeen uniek, maar gelyk en het albei dieselfde menseregte wat beskerm moet word. Hierdie standpunt is in die antieke tyd gevestig toe die vrou in alle kulture minderwaardig geag is. In die Afrikakonteks is die ontwikkeling van die sosiale posisie van die vrou van besondere belang omdat baie ongewenste diskriminasie in dié verband nog aanwesig is. Daarom is dit verblydend dat die grondwet voorsiening maak vir die bestaan van 'n kommissie vir Geslagsgelykheid wat die idee moet bevorder (Hoofstuk 9).

\subsection{Ordelikheid}

In hoofstuk 8 van die grondwet word die pligte van howe en die algemene beginsels van regspleging behandel. Die samestelling van die howe en die regsproses word, vanuit teologies-etiese hoek gesien, doeltreffend uitgespel. Regte en verantwoordelikhede word op gebalanseerde wyse behandel en voorsiening word gemaak vir die uitroep van noodtoestande met duidelike voorwaardes. Hoewel die samestelling van die regering, soos beskryf in hoofstuk 5, berus op die uitgangspunt van meerderheidsregering sonder verpligte koalisievorming met minderheidspartye, is die moontlikheid van opposisie en vreedsame protes ingebou. In hoofstuk 11 word die prinsipes en funksionering van die veiligheidsdienste doeltreffend uitgespel. Ook die beginsels van finansiële bestuur bied 'n basis vir gesonde ekonomiese beleidstoepassing.

Die nuwe grondwet gee in sy geheel nie blyke daarvan dat dit die koninkryk van God doelbewus en aktief ondermyn nie. Weliswaar is daar elemente ingebou waarmee gelowiges sal verskil soos op verskeie punte in hierdie artikel aangetoon word. Die kritiek bied egter nie rede vir burgerlike ongehoorsaamheid en die nie- 
erkenning van die wettige owerheid nie. Daarby moet gelet word op die feit dat die owerheid op demokratiese wyse vervang kan word.

Uit bogenoemde blyk dit dat daar genoeg rede is om te sê dat die grondwet voldoende ruimte bied vir die handhawing van orde op 'n demokratiese wyse. Die grondwet op sigself waarborg egter nie 'n ordelike samelewing nie. 'n Ordelike samelewing is alleen moontlik waar toekomstige regerings die wil en vermoë het om ordelik te regeer. Dit bly dus die verantwoordelikheid van die toekomstige regerings, die opposisie, die openbare media as waghond en die konstitusionele hof om toe te sien dat volgens die beginsels geregeer word. Teologies-eties gesien, kan egter tot die konklusie gekom word dat die grondwet op sigself ' $n$ gesonde basis bied vir die handhawing van orde.

\subsection{Godsdiensvryheid}

Die essensiële vereiste van godsdiensvryheid is dat mense die reg moet hê om privaat en openlik, individueel en gemeenskaplik die godsdiens van hulle keuse ongehinderd te beoefen en uit te dra (Von Campenhausen, 1971:37). Die handves van regte spel in artikel 15 uit wat met godsdiensvryheid bedoel word. Vrye godsdiensbeoefening in die samelewing en, onder sekere omstandighede in staatsof staatsondersteunde instellings, word gewaarborg. Daarmee word nie bedoel dat die owerheid homself met 'n bepaalde godsdiens identifiseer nie.

Uit 'n Christelike oogpunt moet die vraag gevra word of die grondwet aan die kerk ruimte bied om sy roeping in die samelewing te vervul en of gelowiges hulle geloof vryelik kan bely en uitleef. Voorts moet ook gevra word of verbondsouers die ruimte gegun word om hulle rol, volgens die doopsbelofte, te vervul. Het gelowiges ook die reg op aanbidding en op bediening deur die bedienaar van sy keuse in staatsinstellings? Op hierdie vrae kan bevestigend geantwoord word. Die grondwet bied voldoende ruimte vir die uitlewing van artikel 36 van die Nederlandse Geloofsbelydenis. Wat wel kommer wek, is die feit dat die reg op godsdiensuryheid tydens noodtoestande beperk kan word (art. 37:5). Hierdie bepaling gee ruimte vir magsmisbruik deur die owerheid in 'n tyd van oorlog of algemene oproer en skakel nie die gevaar van godsdiensvervolging uit nie. In sodanige omstandighede is die kerk uitgelewer aan die welwillendheid van die owerheid wat aan bewind is en so 'n situasie behoort vermy te word.

\section{Konklusie}

In sy geheel kan die nuwe grondwet, vanuit gereformeerde teologies-etiese hoek besien, positief gewaardeer word. Voldoende ruimte word gebied vir die handhawing van die beginsels van geregtigheid, orde en godsdiensvryheid. In dié opsig is die grondwet 'n groot verbetering op die vorige grondwette waardeur die samelewing in Suid-Afrika gereêl is. 
'n Grondwet moet egter gedra word deur 'n algemene demokratiese ingesteldheid en ' $n$ kultuur van menseregte onder die bevolking - anders is dit van geen waarde nie. Aan so ' $n$ kultuur is daar in Suid-Afrika nog 'n groot gebrek (Jordaan, 1994:33). Daarom is die beklemtoning van die beginsel van menseregte nou belangrik juis omdat daar ten opsigte van etiese beginsels 'n voortdurende wisselwerking is tussen Bybel en situasie (König, 1993:56). Die kerk het die verpligting om die wetlike erkenning van die regte van mense in die samelewing te beklemtoon (Kik, 1982:91; Höffe, 1982:246). Veral in die huidige tyd is die uitvoering van hierdie taak in Suid-Afrika dus belangrik. Dit is nou van groot belang dat Christene, in die vervulling van hulle politieke rol, en die geïnstitueerde kerk in sy profeties-kritiese roeping, prinsipieel-etiese getuienis lewer ten gunste van die beskerming en die handhawing van menseregte. Sodoende kan vanuit Christelike kant bygedra word tot die vestiging van 'n positiewe gesindheid ten opsigte van 'n kultuur van demokrasie en menseregte

\section{Bibliografie}

CARSA

Kyk

CONSTITUTIONAL ASSEMBLY OF THE REPUBLIC OF SOUTH AFRICA.

CONSTITUTIONAL ASSEMBLY OF THE REPUBLIC OF SOUTH AFRICA 1996 Annual Report 1996. Pretoria : Staatsdrukkery.

DE BRUYN, P.J. 1993. The Ten Commandments. Midrand : Varia Publishers.

DE GRUCHY, J.W. 1984. Bonhoeffer and South Africa. Grand Rapids : Eerdmans.

DU TOIT, D.A. 1988. Die mens en sy regte. Kaapstad : Zebra Publikasies

ELOFF T. 1982. Die subordineringsopdrag aan die owerhede. 'n Eksegeties-dogmatiese studie. Potchefstroom : PU vir CHO. (Th.M.-verhandeling.)

ELOFF, T. 1988. Staatsowerheid en geregtigheid met besondere verwysing na rasseklasssifikasie. 'n Teologies-etiese studie. Potchefstroom : PU vir CHO. (Th.D.proefskrif.)

GEREFORMEERDE EKUMENIESE SINODE. 1983. RES Testimony of Human Rights. Grand Rapids : Reformed Ecumenical Synod.

GEREFORMEERDE KERKE IN SUID-AFRIKA. 1985. Handelinge van die twee-enveertigste Nasionale Sinode. Potchefstroom : Potchefstroom Herald.

GEREFORMEERDE KERKE IN SUID-AFRIKA. 1994. Handelinge van die vyf-enveertigste Nasionale Sinode. Potchefstroom : Potchefstroom Herald

GKSA.

\section{$K y k$}

GEREFORMEERDE KERKE IN SUID-AFRIKA

GRONDWETLIKE VERGADERING REPUBLIEK VAN SUID-AFRIKA. 1996. Wetsontwerp op die grondwet van die Republiek van Suid-Afrika. 7 Mei 1996. Soos gewysig deur die Grondwetlike Komitee. Pretoria : Staatsdrukker. 
GVRSA
$K y k$
GRONDWETLIKE VERGADERING REPUBLIEK VAN SUID-AFRIKA

HOFFE, O. 1982. Die Menschenrechten in der Kirche. (In Hertz, A. e.a. Handbuch der Christlichen Ethik. Freiburg : Gutersloher Verlaghaus Gerd Mohn. p. 236-255.)

HORNER, F. 1982. Ethische Kriterien fur die Entwicklung sozialer Grundrechte. (In Hertz, A e.a. Handbuch der Christlichen Ethik. Freiburg : Gutersloher Verlaghaus Gerd Mohn. p. 221-235.)

JORDAAN, W.J. 1994. Menseregte: 'n Sielkundige perspektief. (In Vos, C.J.H. \& Müller, J.C. Menswaardig. Halfway House : Orion Uitgewers. p. 33-550.)

KIK, A. 1982. Geloof in menschenrechten. Kampen : Kok.

KLEYN, D.G. \& HEYNS, C.H. 1994. Menslike waardigheid en 'n menseregte-handves vir Suid-Afrika. (In Vos, C.J.H. \& Müller, J.C. Menswaardig. Halfway House : Orion Uitgewers. p. 16-25.)

KÖNIG, A. 1993. Menslike mense. Gelowig nagedink deel 5. Oor die mens en die sonde in die praktyk. Halfway House : Orion Uitgewers.

KÖNIG, A. 1994. Die waarde van die mens. (In Vos, C.J.H. \& Müller J.C. Menswaardig. Halfway House : Orion Uitgewers. p. 7-15.)

KOSHY, N. 1996. The ecumenical understanding of religious liberty: The contribution of the World Council of Churches. Journal of Church and State, 38(1): 137-154, Jan.

LENDVAI, P. 1983. Religionsfreiheit und Menschenrechte. Billanz und Aussicht. Köln : Verlag Styria.

LOCHMAN, J.M. 1976. Um eine christliche Perspektive für Menschenrechte. (In Lochman, J.M. \& Moltmann, J. Gottes Recht und Menschenrechte. Bielefeld : Klemme und Bleimund. p. 7-19.)

MOLTMANN, J. 1977. A definite study paper: A Christian declaration on human rights. (In Miller, A.O. ed. A Christian declaration on human rights. Theological studies of the World Alliance of the Reformed Churches. Grand Rapids : Eerdmans. p. 129-143.)

NEDERDUITSE GEREFORMEERDE KERK. 1986. Church and society. A testimony of the Dutch Reformed Church. Bloemfontein : Pro Christo Publishers

NGK.

\section{Kyk}

NEDERDUITSE GEREFORMEERDE KERK.

SALADIN, P. 1982. Die Rechtsgeitung von Menschenrechten als Beispiel für die Rechtserheblichkeit etischer Kriterien. (In Hertz, A. e.a. Handbuch der Christlichen Ethik. Freiburg : Gutersloher Verlaghaus Gerd Mohn. p. 197-220.)

UCA

\section{Kyk}

United Christian Action.

UNITED CHRISTIAN ACTION. 1995. The Christian voice of Southern Africa. Durbanville : The Christian Voice.

VAN DER VYVER, J.D. 1974. Menseregte. Potchefstroom : Instituut vir die Bevordering van Calvinisme. 
VAN DER WALT, B.J. 1983. Die staat in die lig van die Bybel. Potchefstroom : PU vir $\mathrm{CHO}$

VILLA-VICENCIO, C. 1992. A theology of reconstruction. Cambridge : University Press.

VISAGIE, J. 1994. Menseregte en die kerk. (In Vos, C.J.A. \& Müller, J.C. Menswaardig. Halfway House : Orion Uitgewers. p. 16-25.)

VON CAMPENHAUSEN, A.F. 1971. Religionsfreiheit. Gottingen : Vanden Hoeck und Ruprecht.

VORSTER, J.M. 1993. Godsdiensvryheid in 'n toekomstige Suid-Afrika in die lig van artikel 36 van die Nederlandse Geloofsbelydenis. In die Skriflig, 27(3):307-32 1, Sept.

WINGREN, G. 1978. Menschenrechten - een theologische analyse. (In Ter Vrugt-Lenz, J. \& Van der Voort, I.N.A. Menschenrechten in oost en west. Leusden : Algemeen Diakonaal Bureau van de Gereformeerde Kerken in Nederland. p. 16-22.) 
